\title{
1 Effects of personal air pollution exposure on asthma symptoms, lung function and airway
}

\section{2 inflammation}

3

$4 \quad{ }^{1}$ Lucy Chambers BSc

$5{ }^{1}$ Joanne Finch RN

$6 \quad{ }^{1}$ Karen Edwards RN

$7 \quad{ }^{2}$ Antoine Jeanjean $\mathrm{PhD}$

$8 \quad{ }^{2}$ Roland Leigh $\mathrm{PhD}$

$9 \quad{ }^{1}$ Sherif Gonem PhD

10

$11{ }^{1}$ NIHR Leicester Biomedical Research Centre, Glenfield Hospital, Groby Road, Leicester

$12 \quad{ }^{2}$ Department of Physics and Astronomy, University of Leicester, Leicester

13

14

15 Address for correspondence:

16 Dr. Sherif Gonem

17 NIHR Biomedical Research Centre (Respiratory)

18 Glenfield Hospital

19 Groby Road

20 Leicester

21 LE3 9QP, UK

22 Tel: 00441162583486

23 E-mail: sg330@le.ac.uk 
Funding: This paper presents independent research funded by the National Institute for Health Research (NIHR). The views expressed are those of the authors and not necessarily those of the NHS, the NIHR or the Department of Health. This work was funded by an Academy of Medical Sciences Starter Grant, supported by the Academy of Medical Sciences, Wellcome Trust, Medical Research Council, British Heart Foundation, Arthritis Research UK, Royal College of Physicians and Diabetes UK, and by the Midlands Asthma and Allergy Research Association. SG is funded by an NIHR Clinical Lectureship. LC was supported by a Wolfson Foundation Intercalated Degree Award. The authors thank the University of Leicester and EarthSense System Ltd for funding the development of the satellite dataset used in this study. 


\section{Abstract}

52

\section{Background}

54

There is evidence that air pollution increases the risk of asthma hospitalisations and healthcare utilisation, but the effects on day-to-day asthma control are not fully understood.

\section{Objective}

58

We undertook a prospective single-centre panel study to test the hypothesis that personal air pollution exposure is associated with asthma symptoms, lung function and airway inflammation.

\section{Methods}

Thirty-two patients with a clinical diagnosis of asthma were provided with a personal air pollution monitor (Cairclip $\mathrm{NO}_{2} / \mathrm{O}_{3}$ ) which was kept on or around their person throughout the 12-week follow-up period. Ambient levels of $\mathrm{NO}_{2}$ and particulate matter were modelled based upon satellite imaging data. Directly measured ozone, $\mathrm{NO}_{2}$ and particulate matter levels were obtained from a monitoring station in central Leicester. Participants made daily electronic records of asthma symptoms, peak expiratory flow, and exhaled nitric oxide. Spirometry and asthma symptom questionnaires were completed at fortnightly study visits. Data were analysed using linear mixed effects models and cross-correlation.

\section{Results}

Cairclip exposure data were of good quality with clear evidence of diurnal variability and a missing data rate of approximately $20 \%$. We were unable to detect consistent relationships between personal air pollution exposure and clinical outcomes in the group as a whole. In an 
exploratory subgroup analysis, total oxidant exposure was associated with increased daytime symptoms in women but not men.

\section{Conclusions and clinical relevance}

We did not find compelling evidence that air pollution exposure impacts on day-to-day clinical control in an unselected asthma population, but further studies are required in larger populations with higher exposure levels. Women may be more susceptible than men to the effects of air pollution, an observation which requires confirmation in future studies.

\section{(1)}

85

6

7

8


Ambient air pollution exposure contributes substantially to the global burden of disease, with particulate matter pollution being the fifth-ranking mortality risk factor worldwide in 2015 [1]. The majority of this excess mortality is attributable to cardiovascular and respiratory conditions such as ischaemic heart disease and chronic obstructive airways disease. Air pollution is mainly derived from the combustion of fossil fuels and comprises a number of distinct chemical constituents. These include gaseous pollutants such as nitrogen oxides and ozone, and particulate matter which may be further sub-divided into fine (aerodynamic diameter $<2.5 \mu \mathrm{m}$, $\mathrm{PM}_{2.5}$ ) and coarse (aerodynamic diameter between 2.5 and $10 \mu \mathrm{m}, \mathrm{PM}_{10}$ ).

There is at present limited information available regarding the effects of air pollution exposure on individual patients in a real-life setting. This is primarily due to the difficulty of accurately evaluating personal exposures and correlating these with day-to-day variations in disease control. However, increasing miniaturisation of air quality monitors over the past five years has now made personal exposure monitoring a realistic prospect [2]. Furthermore, satellite remote sensing with geospatial modelling of ground-level air pollution is emerging as an important source of exposure data in epidemiological and cohort studies [3].

Evidence from epidemiological and experimental studies suggests that air pollution may contribute to exacerbations of asthma through oxidative injury to the airways, increased sensitisation to aeroallergens, airway remodelling and airway hyperresponsiveness [4]. We therefore hypothesised that personal air pollution exposure is associated with day-to-day variations in asthma symptoms, lung function and airway inflammation. In order to test this 
hypothesis we undertook a prospective single-centre panel study, making use of portable sensors and satellite-based geospatial modelling.

\section{Methods}

\section{Participants}

Thirty-two patients with asthma were recruited from general respiratory and specialist clinics at Glenfield Hospital, Leicester. Patients were seen at baseline in the stable state, with no changes having been made to their regular inhaled or oral asthma therapy within the preceding six weeks. All participants were never smokers or ex-smokers with less than 10 pack years' smoking history. Asthma was diagnosed in a secondary or tertiary care setting according to British Thoracic Society guidelines [5]. The study was approved by the National Research and Ethics Committee - East Midlands, Leicester, and all participants gave their written informed consent. Participants were recruited and studied on a rolling basis from May 2016 to April 2017.

\section{Exposure measurements}

Participants were provided with a Cairclip $\mathrm{NO}_{2} / \mathrm{O}_{3}$ monitor (Cairpol, La Roche-Blanche, France), a cylindrical unit with a weight of $55 \mathrm{~g}$, length of $62 \mathrm{~mm}$ and diameter of $32 \mathrm{~mm}$. The unit uses an electrochemical sensor to sample total oxidants (the sum of $\mathrm{NO}_{2}$ and $\mathrm{O}_{3}$ ) in the ambient air once per minute, and stores readings with an accurate date and time stamp. Cairclip $\mathrm{NO}_{2} / \mathrm{O}_{3}$ has undergone detailed technical validation by the Joint Research Centre of the European Commission [6] and the United States Environment Protection Agency [7]. The Cairclip unit was kept within a fabric holder which could be easily attached to a belt or handbag. 
Participants were instructed to keep the Cairclip on their person when outdoors, and in close

151

152 proximity to them when indoors. The battery life of the unit was approximately 24 hours and it therefore required charging overnight using a universal serial bus (USB) cable. The same USB connection was used to extract data from the unit at study visits. The unit was set to store 15 minute average readings so as not to exceed its data storage capacity between the twoweekly study visits.

Directly measured daily average levels of $\mathrm{NO}_{2}, \mathrm{O}_{3}$ and $\mathrm{PM}_{2.5}$ at the primary air quality monitoring station in central Leicester were obtained from the Department for the Environment, Food and Rural Affairs (DEFRA) (https://uk-air.defra.gov.uk/data/). Modelled average daily levels of $\mathrm{NO}_{2}, \mathrm{PM}_{10}$ and $\mathrm{PM}_{2.5}$ were produced by the Earth Observation Science Group at the University of Leicester with a spatial resolution of $1 \mathrm{~km}^{2}$. This dataset was derived from satellite data from the European ENSEMBLE model, which corresponds to the median of seven European air quality models provided by Copernicus Atmosphere [8, 9]. The ENSEMBLE model provides surface levels of daily mean values of $\mathrm{NO}_{2}, \mathrm{PM}_{2.5}$ and $\mathrm{PM}_{10}$ at a spatial resolution of $0.1^{\circ}$ (around $7 \mathrm{~km}$ ). These were interpolated onto a $1 \mathrm{~km}$ grid scale based upon DEFRA national pollution climate mapping [10]. Figure 1 shows annual mean $\mathrm{NO}_{2}$ concentrations in 2016 for the City of Leicester calculated using this methodology. Exposures for each participant were calculated based upon the grid square in which their home address was located.

\section{Daily home monitoring}

In order to provide daily time series of clinical outcomes, participants were provided with an electronic symptom diary and peak expiratory flow (PEF) meter (Micro Diary; Carefusion, Basingstoke, UK) and a portable exhaled nitric oxide (FeNO) monitor (NOBreath; Bedfont, 
Maidstone, UK). Participants used the Micro Diary unit twice per day in the morning and evening to record visual analogue scores for cough, breathlessness and wheeze over the preceding overnight or daytime period. These were recorded on an integer scale from zero (no symptoms) to ten (severe symptoms). Total night-time and daytime symptom scores (on an integer scale of zero to thirty) were calculated as the sum of the three visual analogue scores for the preceding overnight or daytime period. Participants also undertook three PEF measurements in the morning and evening using the same unit, and the best of the three readings was recorded on each occasion.

Two measurements of FeNO were made each morning using the NOBreath unit, at an exhalation rate of $50 \mathrm{ml} / \mathrm{s}$. These were manually entered by patients into the Micro Diary since NOBreath does not have the facility for storing multiple test results. The average of the two daily readings was utilised in statistical analysis. We have previously shown that home FeNO monitoring using NOBreath produces reproducible results which correlate well with blood and sputum eosinophil counts [11].

\section{Study visit schedule}

Participants attended a baseline visit at which clinical and demographic details were recorded and the home monitoring equipment was introduced and explained. Participants were then followed up for a total of 12 weeks and attended study visits at 2-weekly intervals, at which time data were downloaded from the Cairclip and Micro Diary units. Participants also completed the Asthma Control Questionnaire [12] and Asthma Quality of Life Questionnaire [13], and underwent spirometry. Spirometry was performed according to American Thoracic Society / European Respiratory Society guidelines [14] with predicted values calculated using 
199 Global Lung Initiative reference equations [15]. Short and long-acting bronchodilators were withheld for 4 and 12 hours respectively before study visits.

201

202

Statistical analysis

Statistical analysis was performed using SPSS 24 (IBM, Armonk, New York, USA).

Relationships between exposure and outcome variables were analysed using linear mixed effects models and cross-correlation, with the two techniques giving complementary information.

Linear mixed effects models were used to assess the relationship between linear trends in the exposure and outcome variables over the study period at a group level, with separate models constructed for each clinical outcome. Clinical outcomes were entered as dependent variables in the model, with exposures specified as fixed effects. An autoregressive covariance structure was specified to account for the observed autocorrelation in the clinical time series. For outcomes measured daily (symptom scores, PEF and FeNO) the corresponding exposure variable was the average total oxidant reading on the same day measured using the Cairclip unit. For outcomes measured at study visits the average total oxidant over the previous two weeks was used as the corresponding exposure variable for spirometry and the Asthma Quality of Life Questionnaire, and over the previous week for the Asthma Control Questionnaire.

Cross-correlation was used to assess the relationship between day-to-day variations in exposure and outcome variables in individual participants over a range of lag times ( -7 to +7 days). Cross-correlation results were assessed individually, and were combined across the group to give the mean and $95 \%$ confidence interval cross-correlation at each lag time. Exploratory 
subgroup analyses were performed, stratifying the group by sex and smoking history (exsmokers versus never smokers).

\section{Statistical power calculation}

The primary analysis was estimation of the effect of average total oxidant exposure on peak expiratory flow across the cohort, analysed using a linear mixed effects model. Calculation of statistical power was performed by Dr. Matthew Richardson (University of Leicester) using a simulation approach, based upon an internal pilot comprising the first six participants in the study. A linear mixed effects model was fitted to the pilot data; the dependent variable was morning PEF (PEFam) and the independent variable was the daily average personal total oxidant concentration (AverageOX). A random intercept for each subject was also included in the model. Estimates for the fixed effect intercept, variance of the random intercept and variance of the error term were obtained from the pilot sample. Values for PEFam were then generated according to the regression equation derived from the pilot data, but allowing the regression coefficient for AverageOX to vary. The random intercept for each subject was assumed to follow a normal distribution, and a normally distributed error term was included in the regression equation. The p-value for the regression coefficient of AverageOX was obtained using 100 simulations, with sample size fixed at $n=30$. Based on the simulation results, it was estimated that this sample size would be sufficient to detect an effect size of AverageOx (ppb) on PEFam (L/min) of approximately 0.7 units with power $=80 \%$ at the $5 \%$ significance level.

\section{$\underline{\text { Results }}$}


247 Thirty-one participants completed the study, with one participant withdrawing at an early stage

248 due to technical problems with the Cairclip unit. Clinical and demographic characteristics of

249 the participants are shown in Table 1. Participants were followed up for an average of 78 days,

250 with a total of 2406 person-days of follow-up. The average missing data rate for daily

251 monitoring was $15.5 \%$ for morning readings, $21.7 \%$ for evening readings and $20.6 \%$ for

252 Cairclip total oxidant data. Missing Cairclip data were usually caused by complete discharge

253 of the internal battery, due to the unit being left off charge overnight. This resulted in loss of

254 the timestamp and necessitated return of the unit to the study centre to be reset. Figure 2 shows

255

256

257

258

259

260

261

262

263

264

265

266

an example time series of personal total oxidant exposure in a single participant measured using Cairclip. This shows the typical diurnal pattern of exposure, with peak levels during daylight hours, and considerable day-to-day variability with regard to average daily exposure. Figure 3 shows the average total oxidant levels measured using Cairclip at different times of the day over 1911 person-days of observations. A peak is seen during day-time hours, with additional small peaks corresponding to the morning and evening rush hours on weekdays. Although exposure levels were slightly lower on weekends compared to weekdays, clinical outcomes did not differ significantly across the seven days of the week, as shown in Supplementary Table S1.

Table 2 shows the results of linear mixed effects models in which the fixed effects of average daily total oxidant exposure measured using Cairclip on clinical outcomes were estimated over the whole study group. In each case, no clinically important or statistically significant effects were observed. Cross-correlation analysis did not reveal any consistent associations between exposure and outcome variables in the study group as a whole, as shown in Figure 4 and Supplementary Figures S1-S6. When the group was stratified by sex, we observed a positive correlation on the same day (lag 0) between total oxidant exposure using Cairclip and daytime 
symptoms in females, but not in males (Figure 5). Stratifying the group by smoking history did not reveal any significant associations.

\section{Discussion}

We report the first panel study of the effects of personal air pollution exposure on adults with asthma in which exposures and outcomes were assessed concurrently over an extended 12week period. We assessed air pollution exposure using three separate methodologies, namely (i) a small portable sensor carried on the person (Cairclip $\left.\mathrm{NO}_{2} / \mathrm{O}_{3}\right)$, (ii) modelled data based on satellite imaging, and (iii) directly measured ambient levels at a central monitoring station. We measured a comprehensive panel of daily clinical outcomes, including asthma symptom scores, peak expiratory flow and exhaled nitric oxide. Most previous longitudinal studies of air pollution effects on asthma have relied solely on central monitoring stations to estimate the exposure of an entire community. A small number of studies have utilised personal air pollution sensors [16-19], but due to the bulky nature of the monitoring equipment the follow-up duration has necessarily been limited. We have for the first time demonstrated the feasibility of longterm personal air pollution exposure monitoring.

We did not observe strong associations between exposures and clinical outcomes, although an exploratory sub-group analysis suggested the possibility of increased daytime symptoms in women exposed to air pollution. A number of possible explanations may be suggested to explain our findings. The participants in our study were recruited from Leicester and the surrounding area. In order to increase the generalisability of our results we did not restrict participation to individuals residing in heavily polluted districts. Therefore, a number of study 
participants lived in rural areas and may not have had sufficient air pollution exposure to impact on their asthma control. Indeed, average peak daily exposure to total oxidant measured using Cairclip monitors was approximately $10 \mathrm{ppb}$ in our study cohort, which is well within UK and European air quality limits [20]. Future studies should therefore focus more specifically on high-risk populations, such as those living and working in inner-city areas. Moreover, our data collection and statistical methods relied on detecting associations between exposure and outcome variables produced by day-to-day variability and linear trends arising naturally. We did not impose an experimental change in exposure, as for instance was done by McCreanor $e t$ $a l$, who measured changes in forced expiratory volume in one second caused by walking down variability in exposures and/or clinical outcomes.

With 31 participants we had sufficient statistical power to detect a $21 \mathrm{~L} / \mathrm{min}$ change in peak expiratory flow in association with a $30 \mathrm{ppb}$ change in total oxidant exposure. It is possible that a true effect existed but that it was too small to detect with our sample size. Indeed, previous cohort studies have often reported smaller effect sizes than this [22]. However, it has been shown that changes in peak expiratory flow of less than $20 \mathrm{~L} / \mathrm{min}$ are unlikely to result in perceptibly increased symptoms [23]. Therefore we considered that our sample size was sufficient to detect clinically important effects on lung function.

We endeavoured to reduce the missing data rate by seeing participants frequently at the study centre (every 2 weeks) and providing them with contact details of investigators who could 
approximately $15-20 \%$ of daily exposure or outcome data were missing, and this may have reduced the chance of observing positive associations.

In this study we particularly investigated the effects or air pollution exposure on day-to-day variations in asthma symptoms, lung function and airway inflammation. It is possible that the major effects of air pollution on asthma relate to other aspects of the condition which our study was not designed to measure, such as exacerbations, hospital admissions and lung function decline. Indeed, a recent meta-analysis of 87 epidemiological studies conducted in multiple cities worldwide concluded that short-term exposure to a number of air pollutants results in significantly increased risks of asthma-related hospital admissions [24]. It has been reported in a recent large population-based cohort study that cumulative air pollution exposure is a significant risk factor for progression from asthma to chronic obstructive pulmonary disease [25]. While significant at a population level, these effects may be too subtle to detect in small panel studies.

Susceptibility to the effects of air pollution varies between individuals and is most likely related to genetic factors [26]. Therefore, it is possible that clinically significant effects of air pollution may be confined to a small but important group of individuals with a combination of biological susceptibility and higher-than-average levels of exposure. Future research should seek to detect individuals at particular risk from air pollution and to develop strategies to mitigate this risk. Our data suggest that women may be more susceptible to the effects of air pollution than men, an observation which is shared with a number of previous studies [27], and which requires further investigation. 
We chose to use total oxidant levels measured using the Cairclip $\mathrm{NO}_{2} / \mathrm{O}_{3}$ monitor as our primary exposure variable. This device was chosen due to a combination of portability, relatively low cost, and good measurement properties (precision, linearity, limits of detection) under laboratory and field conditions $[6,7,28]$. However, these validation studies were performed with the sensor in the static state, and it is known that movement of air pollution sensors can have a significant effect on the measurements [29]. A further consideration for mobile monitoring is the sensor response time, which although relatively fast at between 1.5 and 4 minutes for Cairclip [6, 7] may still not be sufficient to detect very transient increases in air pollution exposure. Therefore sensors used in future personal exposure studies should first undergo validation under realistic field conditions [30]. Jaio et al found that Cairclip $\mathrm{NO}_{2} / \mathrm{O}_{3}$ accurately measured the sum of $\mathrm{NO}_{2}$ and $\mathrm{O}_{3}$ (total oxidants) when compared against reference sensors [31]. However, when an estimate of $\mathrm{NO}_{2}$ was derived by subtracting reference values of $\mathrm{O}_{3}$ from Cairclip total oxidant measurements, these did not correlate with reference values of $\mathrm{NO}_{2}$. This suggests that Cairclip $\mathrm{NO}_{2} / \mathrm{O}_{3}$ measurements are not entirely additive and cannot be used to reliably measure the individual $\mathrm{NO}_{2}$ and $\mathrm{O}_{3}$ components. This is a potential limitation of the study, since it is possible that measuring $\mathrm{NO}_{2}$ or ozone alone would have resulted in greater correlation with clinical outcomes. However, Cairclip $\mathrm{NO}_{2}$ was still in development when our study commenced and is less well validated than Cairclip $\mathrm{NO}_{2} / \mathrm{O}_{3}$ [28]. There are now a number of sensors in development or commercially available, measuring either particulate matter [32] or gaseous pollutants [33,34], which may be used in future personal exposure studies. It is likely that the measurement properties of these sensors will continue to improve as technology develops.

The current challenges and opportunities in the use of sensors to estimate environmental exposures have been recently summarised by Loh et al [2]. While small portable air pollution 
monitors have not yet been fully validated in the ambulatory setting, an alternative approach is to collect location and activity data using Global Positioning System-enabled smartphone applications, and to link these to ambient levels of air pollution measured using static groundlevel monitors or satellite imaging. Furthermore, personal exposure to air pollution is dependent not only on ambient levels but also on the activity being undertaken and the rate of ventilation, which can also be estimated using wearable technology.

In conclusion, we were unable to find compelling evidence that air pollution exposure impacts on day-to-day clinical control in an unselected asthma population, but these results should be taken in the context of the relatively small study population and the low levels of exposure experienced. Future studies should focus on selected individuals who are highly exposed to air pollution due to their lifestyle or place of residence. Our results suggest the possibility of increased susceptibility to air pollution in women compared to men, but this observation requires confirmation in further prospective studies. We have for the first time demonstrated the feasibility of long-term personal exposure monitoring. Sensor technology and geospatial data processing is developing rapidly and will in the near future enable us to further understand the relationship between health and the environment in a variety of long-term medical conditions.

\section{Acknowledgement}

The authors gratefully acknowledge Dr. Matthew Richardson (University of Leicester) who performed the statistical power calculation for the study. 
1) Cohen AJ, Brauer M, Burnett R, Anderson HR, Frostad J, Estep K, Balakrishnan K, Brunekreef B, Dandona L, Dandona R, Feigin V, Freedman G, Hubbell B, Jobling A, Kan H, Knibbs L, Liu Y, Martin R, Morawska L, Pope CA 3rd, Shin H, Straif K, Shaddick G, Thomas M, van Dingenen R, van Donkelaar A, Vos T, Murray CJL, Forouzanfar MH. Estimates and 25-year trends of the global burden of disease attributable to ambient air pollution: an analysis of data from the Global Burden of Diseases Study 2015. Lancet. 2017; 389(10082): 1907-1918.

404

405

2) Loh M, Sarigiannis D, Gotti A, Karakitsios S, Pronk A, Kuijpers E, Annesi-Maesano I, 406 Baiz N, Madureira J, Oliveira Fernandes E, Jerrett M, Cherrie JW. How sensors might help define the external exposome. Int J Environ Res Public Health. 2017; 14(4): 434.

3) Sorek-Hamer M, Just AC, Kloog I. Satellite remote sensing in epidemiological studies.

4) Guarnieri M, Balmes JR. Outdoor air pollution and asthma. Lancet. 2014; 383(9928): 1581-92.

5) British Thoracic Society/Scottish Intercollegiate Guidelines Network, 2016. British Guideline on the Management of Asthma. Available from: https://www.britthoracic.org.uk/standards-of-care/guidelines/btssign-british-guideline-on-themanagement-of-asthma/ 
6) Joint Research Centre, 2013. Report of laboratory and in of micro-sensor for monitoring ambient air pollution: CairClipO3/NO2 of CAIRPOL. Available from: http://publications.jrc.ec.europa.eu/repository/

7) Environmental Protection Agency: Washington, DC, USA, 2014. Sensor Evaluation Report; Report EPA/600/R-14/143. Available from: https://cfpub.epa.gov/si/

8) Peuch VH, Engelen R, Simmons A, Lahoz W, Laj P, Galmarini S. Monitoring atmospheric composition and climate, research in support of the Copernicus/GMES atmospheric service, Special Issue. Atmos. Chem. Phys. 2014.

9) Copernicus Atmosphere, 2016. Final Report MACC-III (Monitoring Atmospheric Composition and Climate 3). Available from: http://atmosphere.copernicus.eu/reports

10) Department for the Environment, Food and Rural Affairs, 2015. 1 km DEFRA national pollution climate mapping for $\mathrm{NO}_{2}, \mathrm{PM}_{10}$ and $\mathrm{PM}_{2.5}$. Available from: https://ukair.defra.gov.uk/data/pcm-data

11) Nanda CR, Singapuri A, Soares M, Monteiro W, Siddiqui S, Gonem S. Domiciliary exhaled nitric oxide and eosinophilic airway inflammation in adults with asthma. Eur Respir J. 2016; 48(1): 242-4.

12) Juniper EF, O'Byrne PM, Guyatt GH, Ferrie PJ, King DR. Development and validation of a questionnaire to measure asthma control. Eur Respir J. 1999; 14(4): 902-7. 
13) Juniper EF, Buist AS, Cox FM, Ferrie PJ, King DR. Validation of a standardized version of the Asthma Quality of Life Questionnaire. Chest. 1999; 115(5): 1265-70.

14) Miller MR, Hankinson J, Brusasco V, Burgos F, Casaburi R, Coates A, Crapo R, Enright P, van der Grinten CP, Gustafsson P, Jensen R, Johnson DC, MacIntyre N, McKay R, Navajas D, Pedersen OF, Pellegrino R, Viegi G, Wanger J; ATS/ERS Task Force. Standardisation of spirometry. Eur Respir J. 2005; 26(2): 319-338.

15) Quanjer PH, Stanojevic S, Cole TJ, Baur X, Hall GL, Enright PL, Hankinson JL, Ip MS, Zheng J, Stocks J. on behalf of the ERS Global Lung Function Initiative. (2012) Multi-ethnic reference values for spirometry for the 3-95 year age range: the global lung function 2012 equations. Eur Respir J. 2012; 40(6): 1324-1343.

16) Delfino RJ, Staimer N, Gillen D, Tjoa T, Sioutas C, Fung K, George SC, Kleinman MT. Personal and ambient air pollution is associated with increased exhaled nitric oxide in children with asthma. Environ Health Perspect. 2006; 114(11): 1736-43.

17) Delfino RJ, Staimer N, Tjoa T, Gillen D, Kleinman MT, Sioutas C, Cooper D. Personal and ambient air pollution exposures and lung function decrements in children with asthma. Environ Health Perspect. 2008; 116(4): 550-8.

18) Spira-Cohen A, Chen LC, Kendall M, Lall R, Thurston GD. Personal exposures to traffic-related air pollution and acute respiratory health among Bronx schoolchildren with asthma. Environ Health Perspect. 2011; 119(4): 559-65. 
19) Smargiassi A, Goldberg MS, Wheeler AJ, Plante C, Valois MF, Mallach G, Kauri LM5, Shutt R, Bartlett S, Raphoz M, Liu L. Associations between personal exposure to air pollutants and lung function tests and cardiovascular indices among children with asthma living near an industrial complex and petroleum refineries. Environ Res. 2014; 132: $38-45$.

20) Department for the Environment, Food and Rural Affairs, 2017. National air quality objectives. Available from: https://uk-air.defra.gov.uk/air-pollution/uk-eu-limits

21) McCreanor J, Cullinan P, Nieuwenhuijsen MJ, Stewart-Evans J, Malliarou E, Jarup L, Harrington R, Svartengren M, Han IK, Ohman-Strickland P, Chung KF, Zhang J. Respiratory effects of exposure to diesel traffic in persons with asthma. $N$ Engl J Med. 2007; 357(23): 2348-58.

22) United States Environmental Protection Agency, 2013. Integrated Science Assessment for Ozone and Related Photochemical Oxidants. Available from: https://www.epa.gov/isa/integrated-science-assessment-isa-ozone-and-relatedphotochemical-oxidants

23) Santanello NC, Zhang J, Seidenberg B, Reiss TF, Barber BL. What are minimal important changes for asthma measures in a clinical trial? Eur Respir J. 1999; 14(1): $23-7$.

24) Zheng XY, Ding H, Jiang LN, Chen SW, Zheng JP, Qiu M, Zhou YX, Chen Q, Guan WJ. Association between Air Pollutants and Asthma Emergency Room Visits and 

Hospital Admissions in Time Series Studies: A Systematic Review and Meta-Analysis. PLoS One. 2015; 10(9): e0138146.

25) To T, Zhu J, Larsen K, Simatovic J, Feldman L, Ryckman K, Gershon A, Lougheed MD, Licskai C, Chen H, Villeneuve PJ, Crighton E, Su Y, Sadatsafavi M, Williams D, Carlsten C; Canadian Respiratory Research Network. Progression from Asthma to Chronic Obstructive Pulmonary Disease. Is Air Pollution a Risk Factor? Am J Respir Crit Care Med. 2016; 194(4): 429-38.

26) Rava M, Smit LA, Nadif R. Gene-environment interactions in the study of asthma in the postgenomewide association studies era. Curr Opin Allergy Clin Immunol. 2015; 15(1): 70-8.

27) Clougherty JE. A growing role for gender analysis in air pollution epidemiology. Environ Health Perspect. 2010; 118(2): 167-76.

28) Duvall RM, Long RW, Beaver MR, Kronmiller KG, Wheeler ML, Szykman JJ. Performance Evaluation and Community Application of Low-Cost Sensors for Ozone and Nitrogen Dioxide. Sensors (Basel). 2016; 16(10). pii: E1698.

29) Lerner U, Yacobi T, Levy I, Moltchanov SA, Cole-Hunter T, Fishbain B. The effect of ego-motion on environmental monitoring. Sci Total Environ. 2015; 533: 8-16.

30) Jerrett M, Donaire-Gonzalez D, Popoola O, Jones R, Cohen RC, Almanza E, de Nazelle A, Mead I, Carrasco-Turigas G, Cole-Hunter T, Triguero-Mas M, Seto E, 
Nieuwenhuijsen M. Validating novel air pollution sensors to improve exposure estimates for epidemiological analyses and citizen science. Environ Res. 2017; 158: 286-294.

31) Jiao W, Hagler G, Williams R, Sharpe R, Brown R, Garver D, Judge R, Caudill M, Rickard J, Davis M, Weinstock L, Zimmer-Dauphinee S, Buckley K. Community Air Sensor Network (CAIRSENSE) project: evaluation of low-cost sensor performance in a suburban environment in the southeastern United States. Atmos Meas Tech. 2016; 9: $5281-5292$.

32) Koehler KA, Peters TM. New Methods for Personal Exposure Monitoring for Airborne Particles. Curr Environ Health Rep. 2015; 2(4): 399-411.

33) McKercher GR, Salmond JA, Vanos JK. Characteristics and applications of small, portable gaseous air pollution monitors. Environ Pollut. 2017; 223: 102-110.

34) Peterson PJD, Aujla A, Grant KH, Brundle AG, Thompson MR, Vande Hey J, Leigh RJ. Practical Use of Metal Oxide Semiconductor Gas Sensors for Measuring Nitrogen Dioxide and Ozone in Urban Environments. Sensors (Basel). 2017; 17(7). pii: E1653. 
Table 1: Clinical and demographic characteristics

\begin{tabular}{|c|c|}
\hline Age (years) & $55.2(13.1)$ \\
\hline Sex & $\begin{array}{l}\text { Female } n=15(48.4 \%) \\
\text { Male } n=16(51.6 \%)\end{array}$ \\
\hline Body mass index $\left(\mathrm{kg} / \mathrm{m}^{2}\right)$ & $30.4(6.7)$ \\
\hline Positive atopic status* (n [\%]) & $24(77.4)$ \\
\hline Duration of asthma (years) & $32.2(21.5)$ \\
\hline Age of onset of asthma (years) & $23.0(21.4)$ \\
\hline $\begin{array}{l}\text { Number of asthma exacerbations in the previous } \\
\text { year }\end{array}$ & $2.4(4.5)$ \\
\hline Regular inhaled corticosteroid use (n [\%]) & $29(93.5)$ \\
\hline $\begin{array}{l}\text { Inhaled corticosteroid dose } \\
\text { (beclometasone dipropionate equivalent }[\mu \mathrm{g}] \text { ) }\end{array}$ & $1000(400-1600)$ \\
\hline Regular oral prednisolone use (n [\%]) & $7(22.6)$ \\
\hline Leukotriene receptor antagonist use (n [\%]) & $7(22.6)$ \\
\hline Oral theophylline use (n [\%]) & $3(9.7)$ \\
\hline Long-acting $\beta_{2}$ agonist use (n [\%]) & $21(67.7)$ \\
\hline Asthma Control Questionnaire score & $1.41(1.15)$ \\
\hline Asthma Quality of Life Questionnaire score & $5.32(1.19)$ \\
\hline $\begin{array}{l}\text { Forced expiratory volume in one second } \\
\text { (\% predicted) }\end{array}$ & $78.6(22.5)$ \\
\hline Forced vital capacity (\% predicted) & $91.1(17.3)$ \\
\hline $\begin{array}{l}\text { Ratio of forced expiratory volume in one second to } \\
\text { forced vital capacity }(\%)\end{array}$ & $67(12)$ \\
\hline Exhaled nitric oxide at a flow rate of $50 \mathrm{ml} / \mathrm{s}(\mathrm{ppb})$ & $28.1(22.3)$ \\
\hline
\end{tabular}

547 Data are $\mathrm{n}(\%)$, mean (standard deviation) or median (interquartile range) unless specified otherwise.

$548 *$ Defined as a positive skin test for any of a panel of specified aeroallergens (grass pollen, tree pollen 549 [alder, silver birch, hazel], moulds [Aspergillus fumigatus, Alternaria tenius, Cladosporium, 550 Penicillium notatum], cat fur, dog dander, and house dust mite [Dermatophagoides pteronyssimus]). 
clinical outcomes

\begin{tabular}{|c|c|c|c|c|}
\hline \multirow{2}{*}{$\begin{array}{l}\text { Outcome measure } \\
\text { (units/range) }\end{array}$} & \multirow{2}{*}{$\begin{array}{l}\text { Estimate } \\
\text { of fixed } \\
\text { effects* }\end{array}$} & \multicolumn{2}{|c|}{ 95\% Confidence Interval } & \multirow{2}{*}{$P$ value } \\
\hline & & $\begin{array}{l}\text { Lower } \\
\text { bound }\end{array}$ & $\begin{array}{l}\text { Upper } \\
\text { bound }\end{array}$ & \\
\hline $\begin{array}{l}\text { Morning PEF } \\
\text { (L/min) }\end{array}$ & 0.038 & -0.416 & 0.491 & 0.870 \\
\hline $\begin{array}{l}\text { Evening PEF } \\
\text { (L/min) }\end{array}$ & -0.088 & -0.576 & 0.400 & 0.723 \\
\hline $\begin{array}{l}\text { FeNO } \\
\text { (ppb) }\end{array}$ & 0.012 & -0.138 & 0.162 & 0.875 \\
\hline $\begin{array}{l}\text { Night-time symptoms } \\
(0-30)\end{array}$ & 0.0036 & -0.0182 & 0.0253 & 0.746 \\
\hline $\begin{array}{l}\text { Daytime symptoms } \\
(0-30)\end{array}$ & 0.0022 & -0.0246 & 0.0290 & 0.872 \\
\hline ACQ (0-6) & 0.0032 & -0.0250 & 0.0314 & 0.822 \\
\hline AQLQ (1-7) & -0.0246 & -0.0613 & 0.0121 & 0.187 \\
\hline $\begin{array}{l}\text { Pre-bronchodilator FEV } 1 \\
\text { (\% predicted) }\end{array}$ & -0.213 & -0.766 & 0.340 & 0.447 \\
\hline $\begin{array}{l}\text { Post-bronchodilator } \\
\text { FEV }_{1} \text { (\% predicted) }\end{array}$ & -0.140 & -0.586 & 0.306 & 0.535 \\
\hline $\begin{array}{l}\text { Pre-bronchodilator FVC } \\
\text { (\% predicted) }\end{array}$ & 0.261 & -0.316 & 0.839 & 0.372 \\
\hline $\begin{array}{l}\text { Post-bronchodilator FVC } \\
\text { (\% predicted) }\end{array}$ & 0.083 & -0.590 & 0.757 & 0.807 \\
\hline $\begin{array}{l}\text { Pre-bronchodilator } \\
\text { FEV1/FVC (\% predicted) }\end{array}$ & -0.0017 & -0.0054 & 0.0021 & 0.385 \\
\hline $\begin{array}{l}\text { Post-bronchodilator } \\
\text { FEV1/FVC (\% predicted) }\end{array}$ & 0.0008 & -0.0023 & 0.0038 & 0.618 \\
\hline
\end{tabular}

$\mathrm{PEF}=$ peak expiratory flow rate $\mathrm{FeNO}=$ exhaled nitric oxide measured at an expiratory flow rate of $50 \mathrm{ml} / \mathrm{s} ; \mathrm{ACQ}=$ Asthma Control Questionnaire score; AQLQ = Asthma Quality of Life Questionnaire score; $\mathrm{FEV}_{1}=$ forced expiratory volume in on second. 
564 Raw satellite pixels from the ENSEMBLE model data (0.1 degrees resolution in latitude and

565 longitude) were interpolated on a $1 \mathrm{~km}$ grid using spatial information from the DEFRA PCM 566 database [10]. Map data are from Google Maps.

567

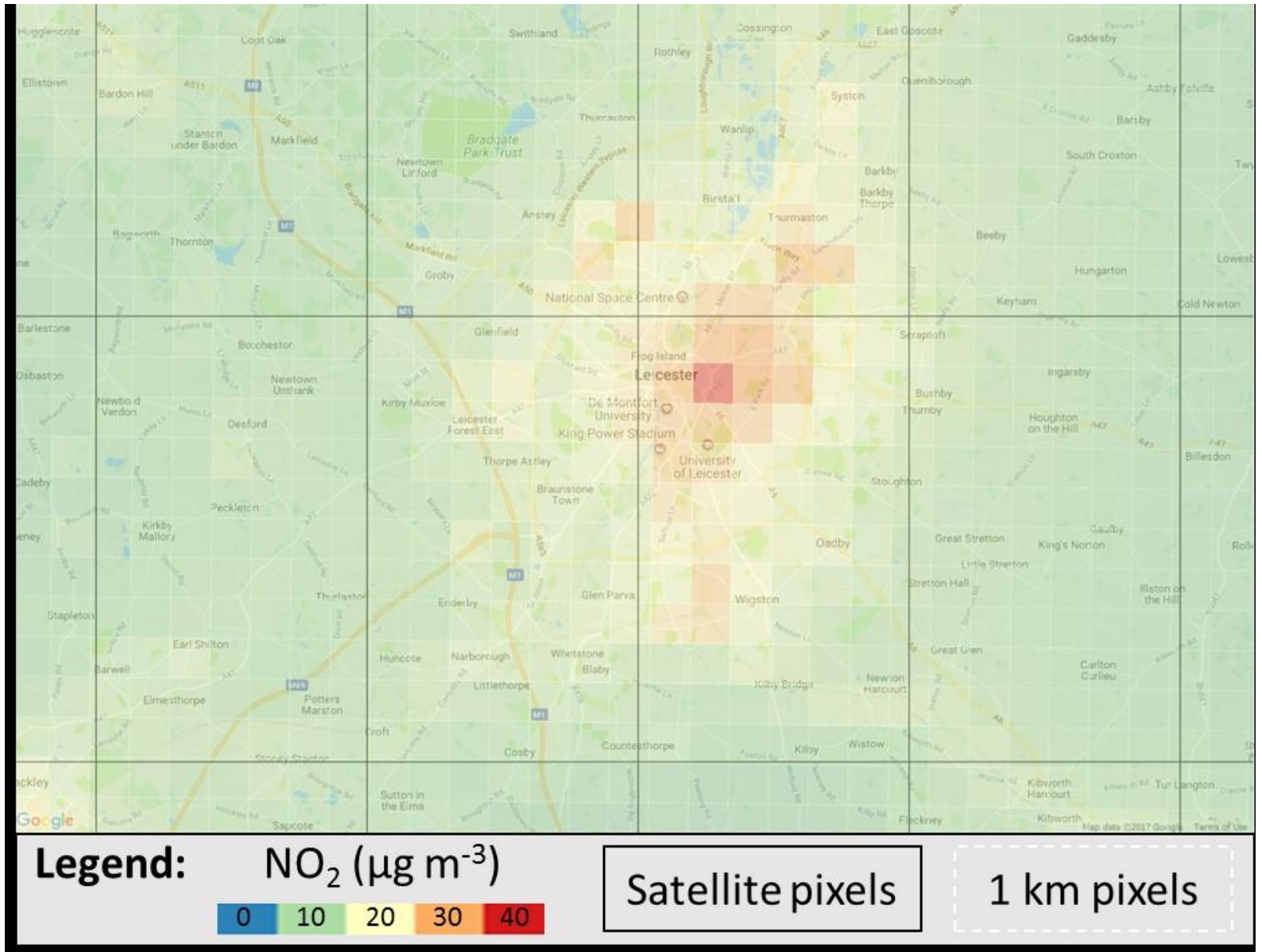


576 Figure 2: Personal total oxidant exposure measured using a Cairclip $\mathrm{NO}_{2} / \mathrm{O}_{3}$ unit in an

577 individual with asthma

578

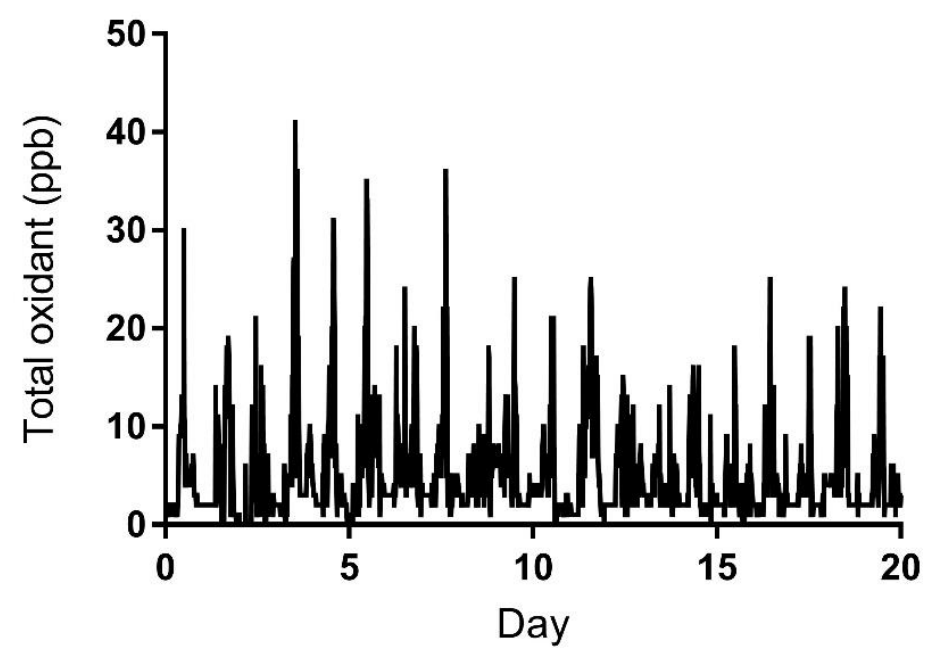

579

580

581

582

583

584

585

586

587

588

589

590

591

592 
594 Average total oxidant levels are shown during the 24-hour daily cycle over 1911 person-days

595 of observations. Results are presented for all days, weekdays (Monday to Friday), and 596 weekends (Saturday and Sunday).

597

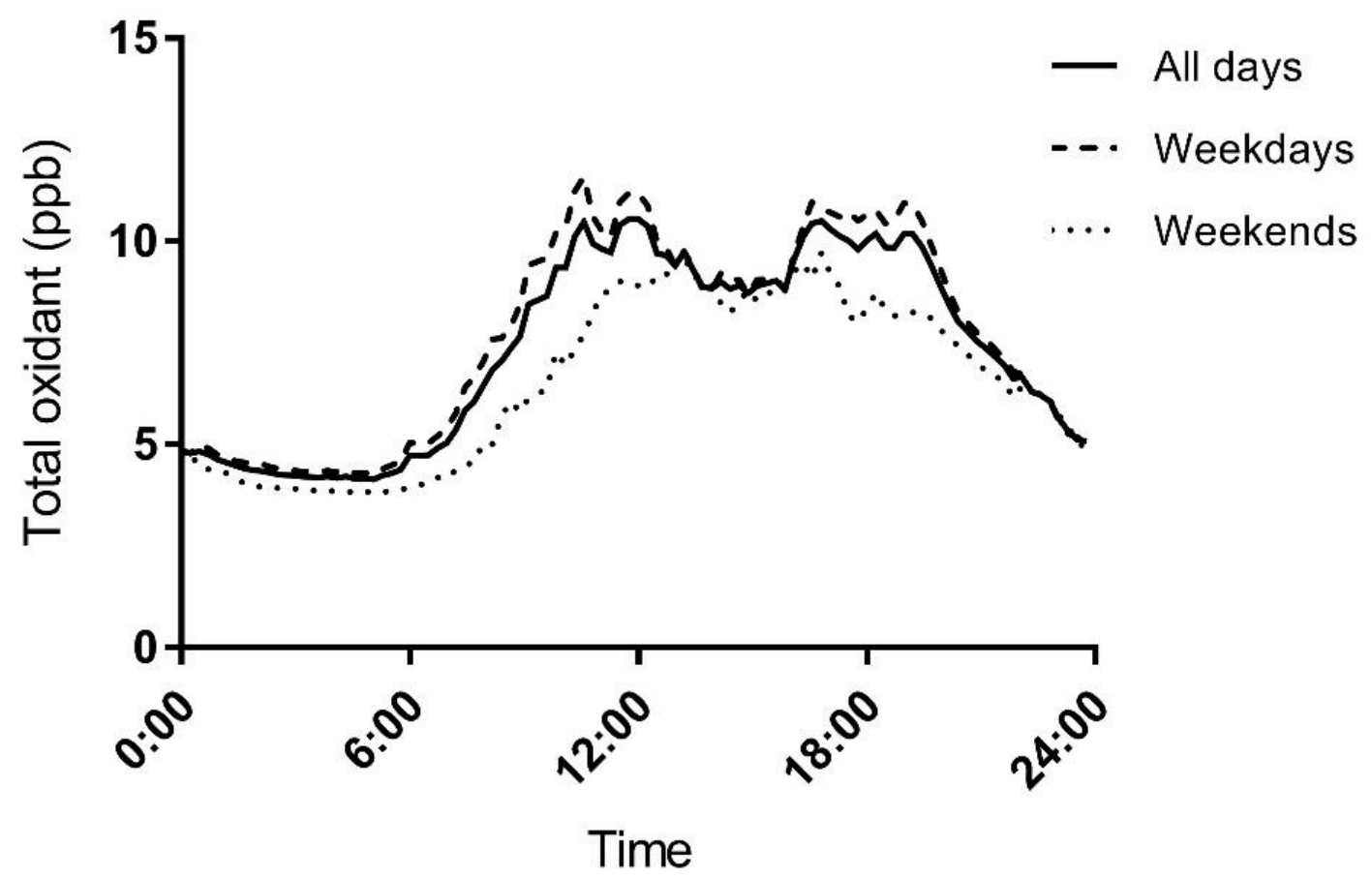

598

599

600

601

602

603

604

605

606

607 

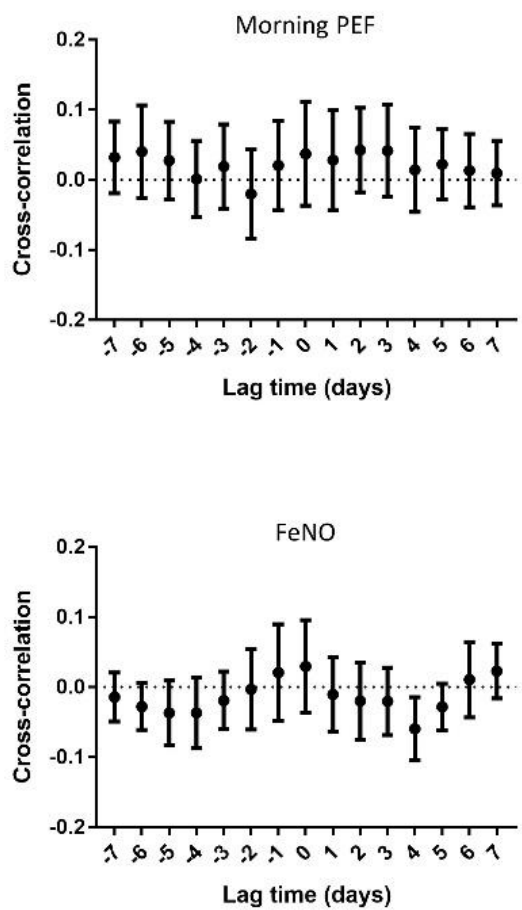
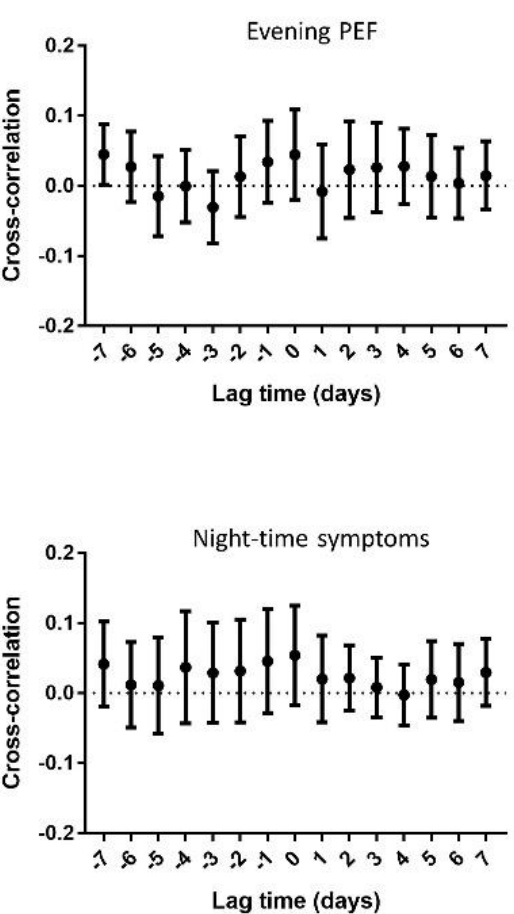
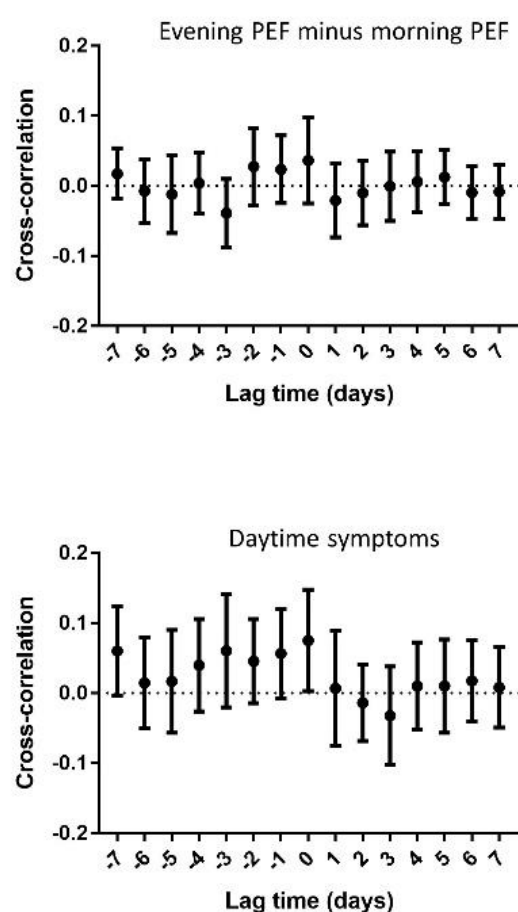
616 Cross-correlations are shown between total oxidant levels measured using Cairclip and daytime

617 symptoms, in female and male participants (Panels A and B respectively). The group mean and $61895 \%$ confidence interval of the cross correlation is shown for each lag time (days). A lag of 619 zero refers to effects occurring on the same day; positive lags refer to changes in outcome 620 preceded by changes in exposure; negative lags refer to changes in exposure preceded by 621 changes in outcome.

622

A

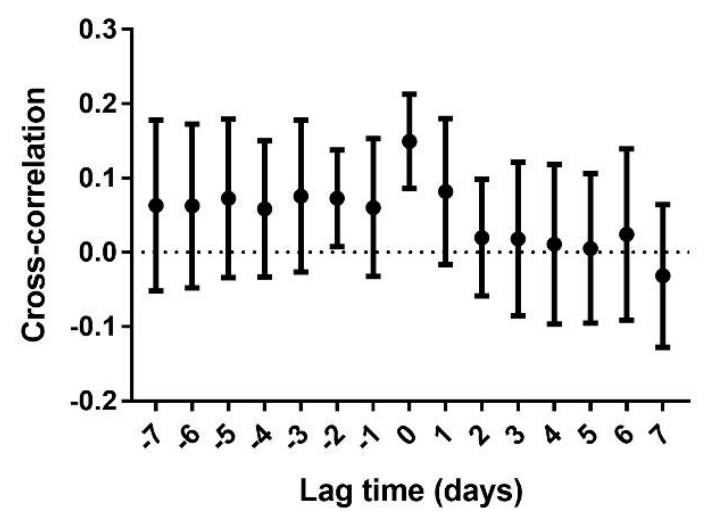

B

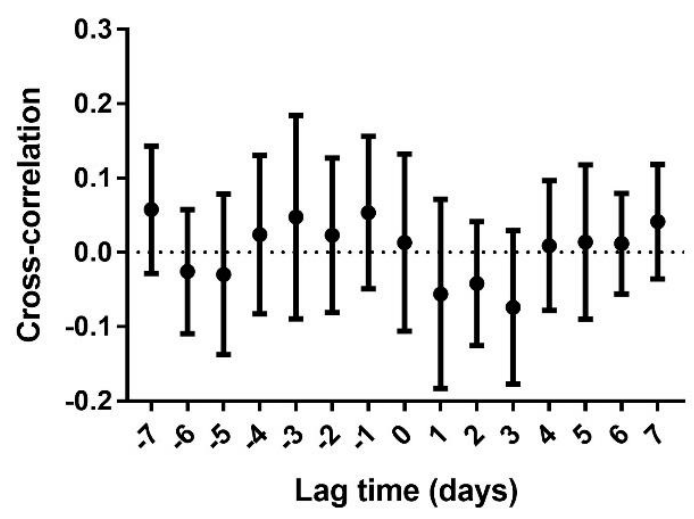

623 
Figure S1: Group-level cross-correlations between directly measured ambient nitrogen dioxide and clinical outcomes

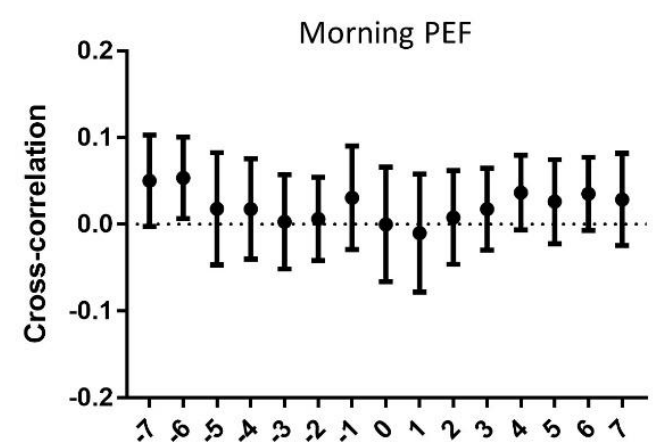

Lag time (days)

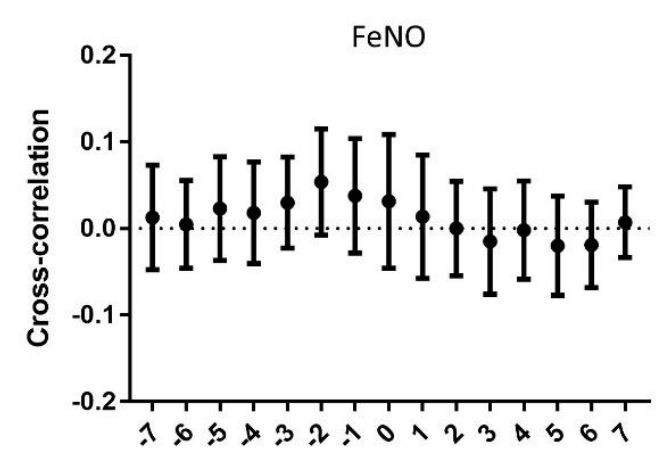

Lag time (days)

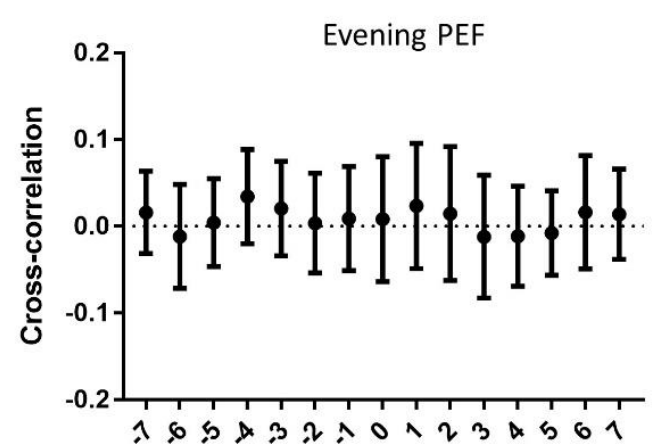

Lag time (days)

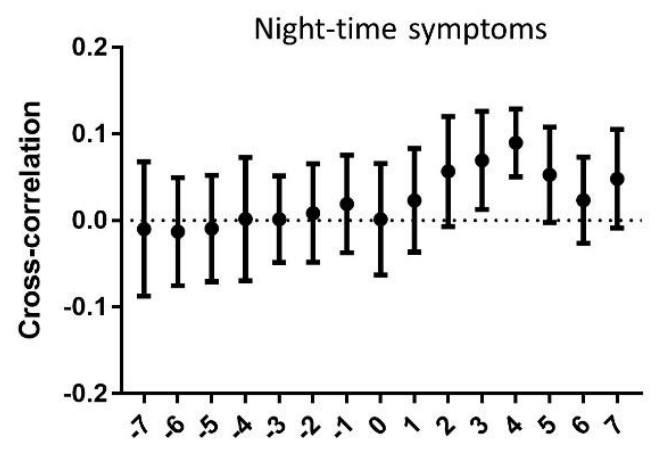

Lag time (days)
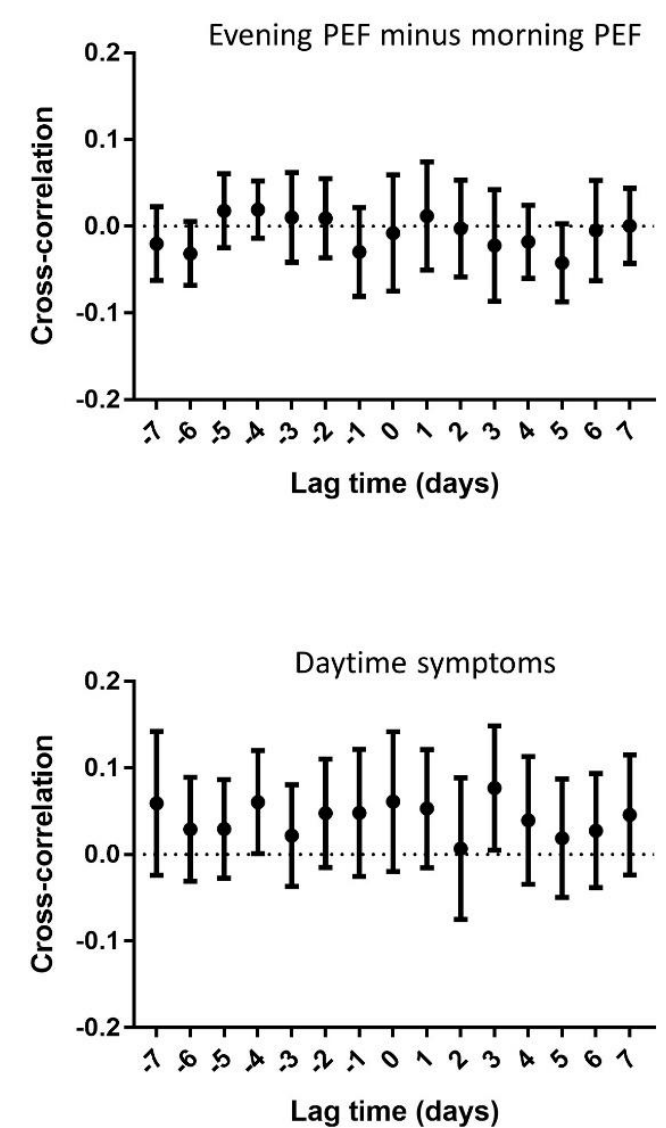
Figure S2: Group-level cross-correlations between directly measured ambient ozone and clinical outcomes
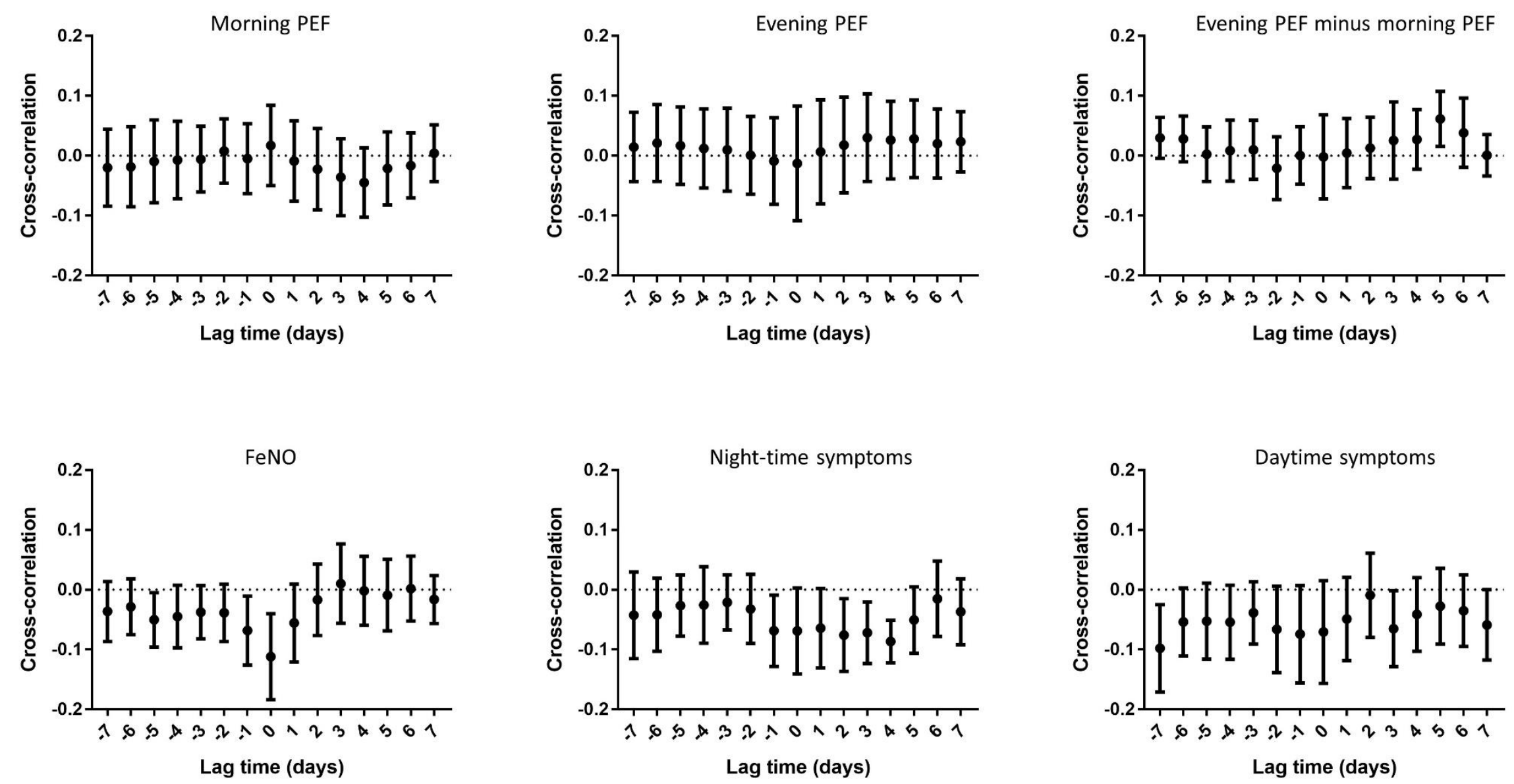
Figure S3: Group-level cross-correlations between directly measured ambient $\mathrm{PM}_{2.5}$ and clinical outcomes
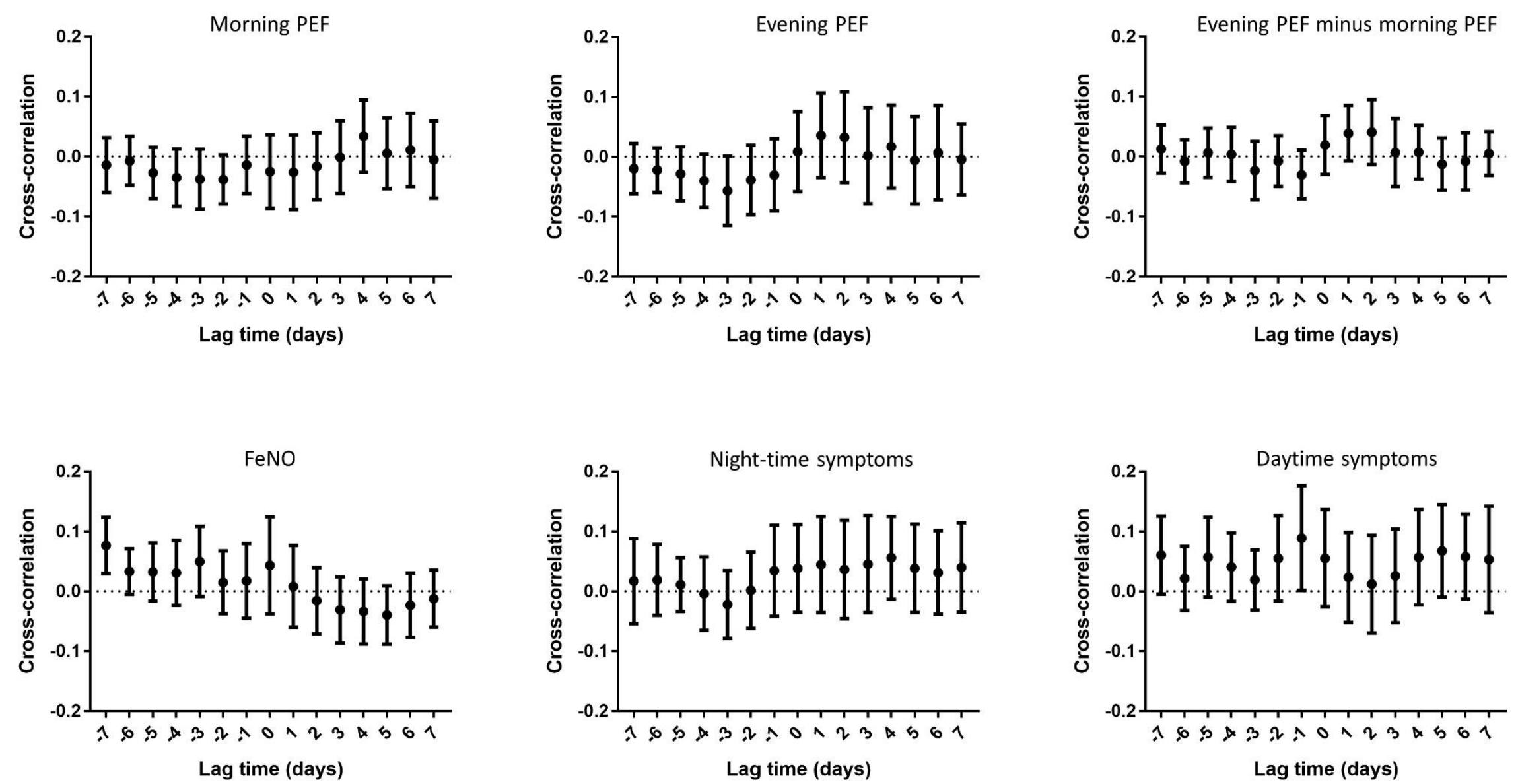
Figure S4: Group-level cross-correlations between modelled ambient nitrogen dioxide and clinical outcomes
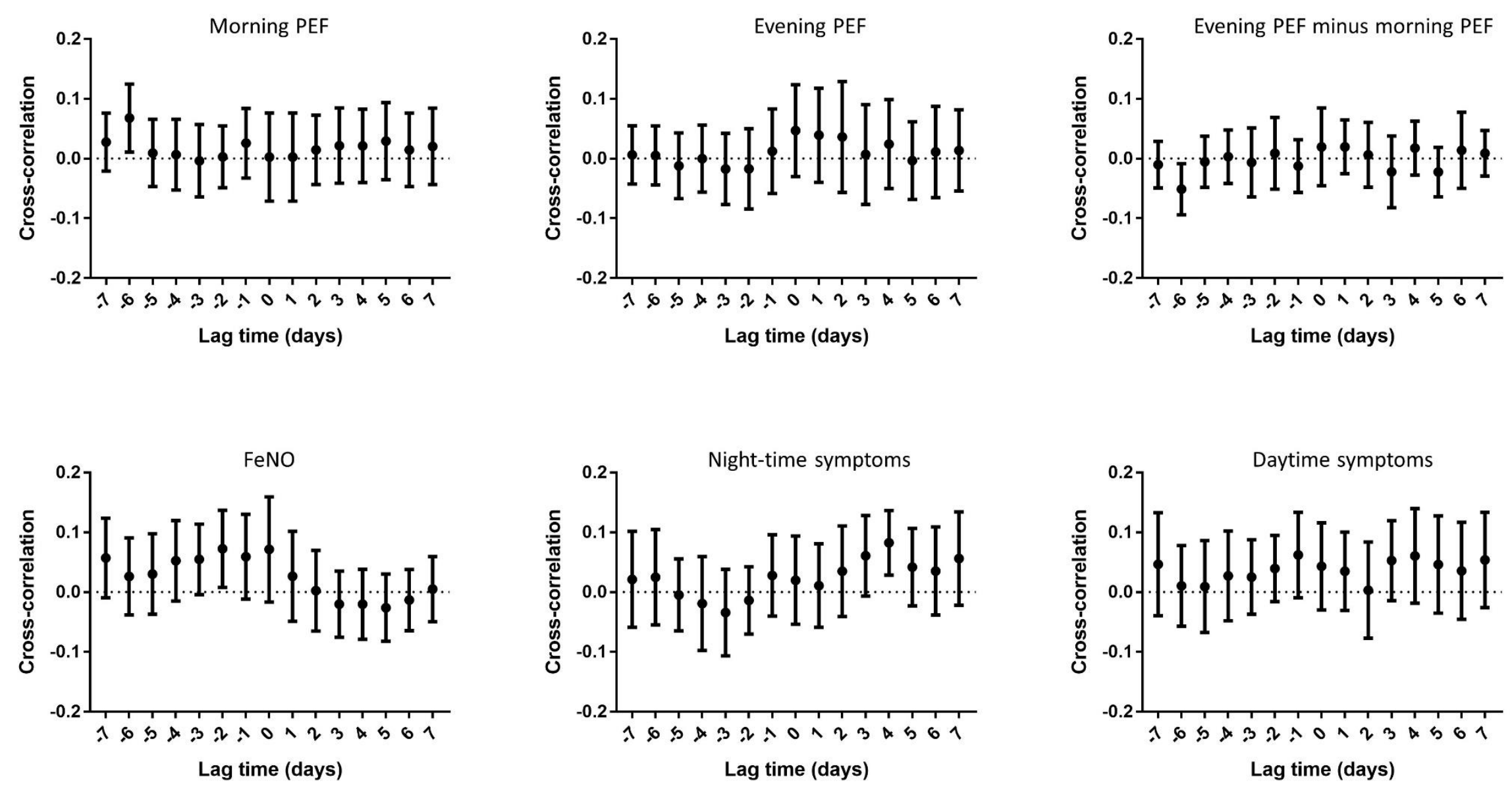
Figure S5: Group-level cross-correlations between modelled ambient $\mathrm{PM}_{10}$ and clinical outcomes
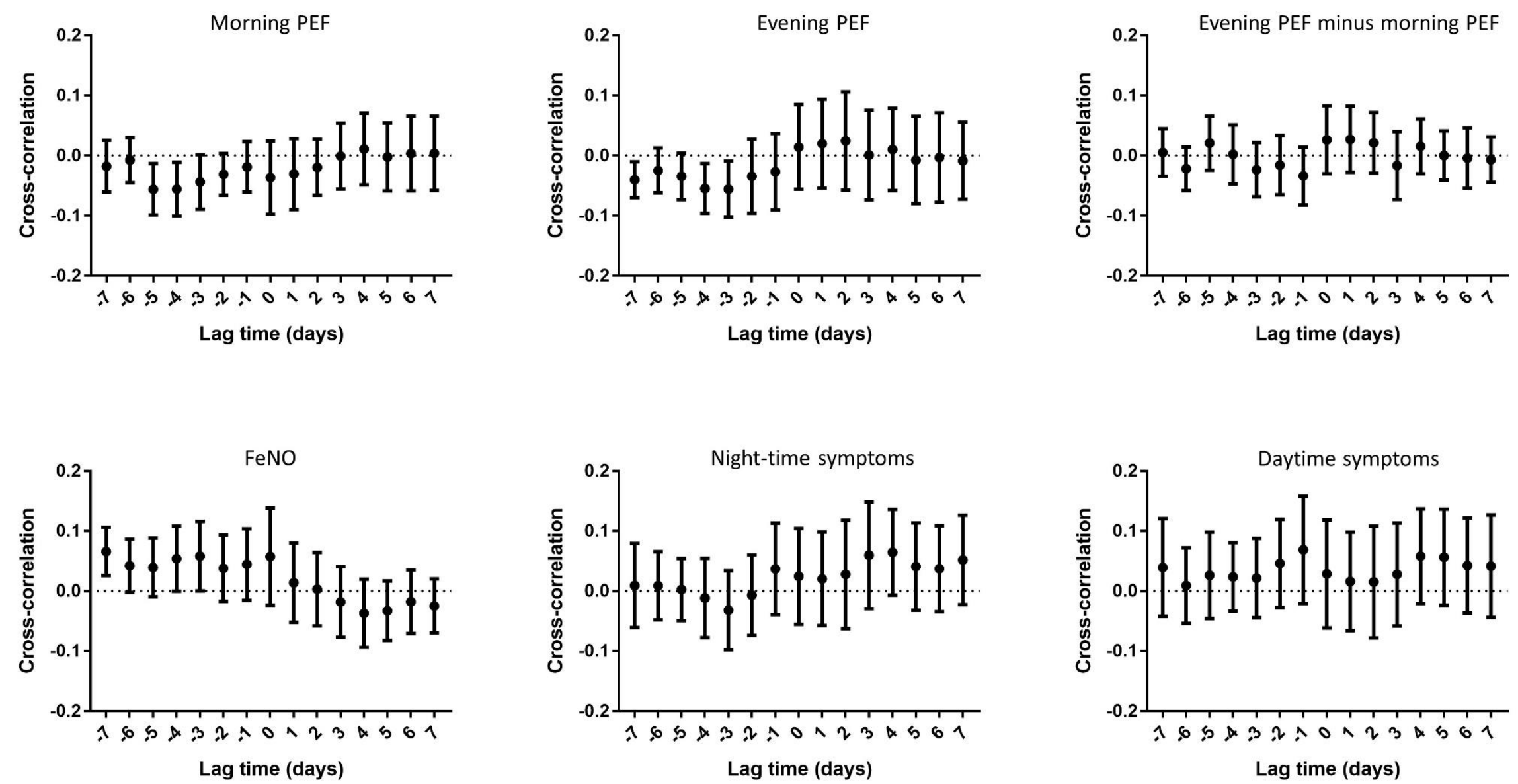
Figure S6: Group-level cross-correlations between modelled ambient $\mathrm{PM}_{2.5}$ and clinical outcomes
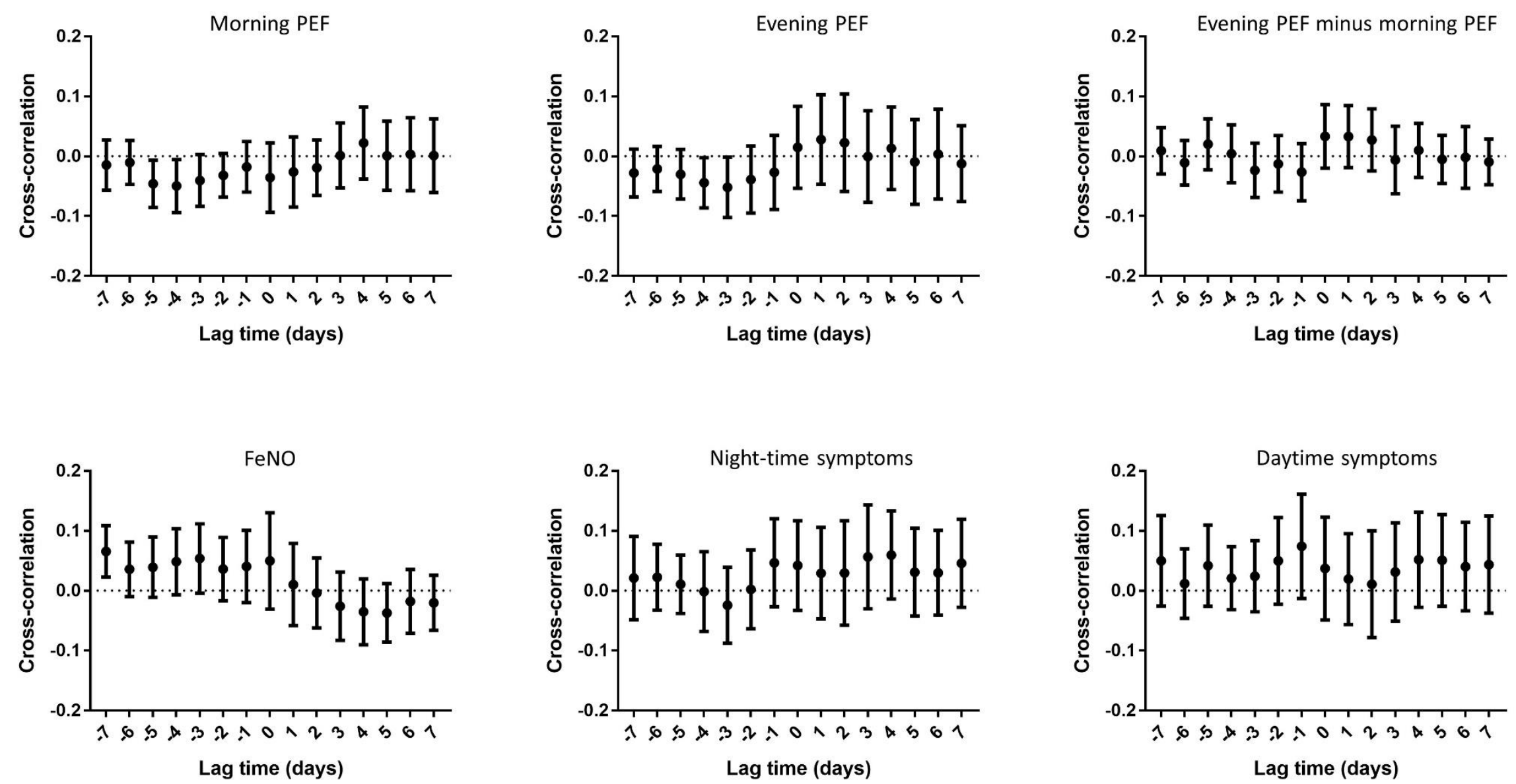